\title{
An Analysis of the Challenges and Benefits of Digital Migration in Zambia
}

\author{
Kashale Chimanga ${ }^{1}$, Phillimon Mumba ${ }^{2}$ \\ ${ }^{1}$ Department of Information and Communication Technology, Copperbelt University, Kapasa Makas Campus, Chinsali, Zambia \\ ${ }^{2}$ School of ICT, Copperbelt University, Riverside Main Campus, Kitwe, Zambia
}

\section{Email address:}

kashalechimanga@gmail.com (K. Chimanga),phillimonmumba@gmail.com (P. Mumba)

To cite this article:

Kashale Chimanga, Phillimon Mumba. An Analysis of the Challenges and Benefits of Digital Migration in Zambia. American Journal of Networks and Communications. Vol. 9, No. 2, 2020, pp. 17-21. doi: 10.11648/j.ajnc.20200902.11

Received: July 3, 2020; Accepted: July 27, 2020; Published: December 11, 2020

\begin{abstract}
Digitization is the current trend in Television broadcasting, both in Zambia and the world over. The International Telecommunication Union (ITU), set 2015 as the year for the entire broadcasting stations in the world to go digital in order to have better signal quality and increase in the capacity of broadcast transmission networks by improving spectrum efficiency. Despite these and many other advantages that come with digital migration, Zambia is yet to realize the full benefits of digital migration implementation. It's against this background that the study was conducted to assess the challenges of digital migration process and its benefits in Zambia. The emphasis was on assessing the television digital migration implementation process; examine the challenges of switching from analogue to digital technology and its benefits. To this effect, a quantitative research design was used on a sample of 300 stakeholders who had direct influence on the process to determine their views. The data collected was analysed using Statistical Package for Social Sciences (SPSS) to categorise the challenges of the migration process and its benefits. The results established that lack of awareness by the public was a major challenge was encountered. In addition, inadequate infrastructure for digital migration coupled with inadequate funding towards the hindered the process of migration. However, the study also established that the country has benefited from migrating from analog to digital broadcasting. Notable ones include; quality of transmission, improved content delivery, and ability of the viewers to view more than one TV channel at once thereby giving them a better viewing pleasure among other benefits. In view of the challenges and benefits of the digital migration to the country, the study recommends that deliberate policies should be put in place to ensure that the infrastructure needed for the digital migration are readily available and that Government should create public awareness with regards to the importance of the digital migration process to allow for more public participation.
\end{abstract}

Keywords: ICT, Digital Migration, Broadcasting Migration, Digital, Benefits and Challenges

\section{Introduction}

In Zambia, just like in many other countries, Television is a popular source of information, a medium of education and entertainment [1]. The analogue and digital technologies comprise the two forms of television broadcasting. The former has been in existence since the onset of television broadcasting in the world. However, due to rapid changes in information and communication technologies (ICTs), analog has been phased out by digital whose myriad features makes it more superior [2].

Digital Broadcasting Migration is a process by which broadcasting services offered on analog networks are transferred to digital networks over a specific period [3]. Zambia, like many other countries in the world has migrated from analog to Digital Television Transmission. The benefits of digital broadcasting stretch to the consumers, broadcasters as well as service providers. The transition from analog transmission to digital broadcast system implies that limited radio frequency will be used in the transfer of television signals [15].

The presentation of numerous differentials is quite 
technical that the traditional terrestrial signal transmission lacks the capacity to provide. A digital signal provides viewers with options to choose their desired content, has high flexibility, besides a place and time of content use via any machine the user decides to use. For example, a portable terminal, a television or even a computer [4].

Digitalization has the potential to offer new openness coupled with diversity to the broadcast sector by developing multiple new channels, through downsizing of the amount of frequencies necessary for one station's broadcast, Zambia has finally migrated from analogue to digital.

This study is therefore aimed at assessing the challenges and benefits of digital migration in Zambia. The study focused its attention on the benefits and challenges associated with digital migration in Zambia.

\subsection{Statement of the Problem}

Over the years now, the analogue television system has been in existence in Zambia. However, the analogue broadcasting techniques has contributed its own quota to the development of broadcasting industry in Zambia and cannot be overemphasized [14]. With the advent of the digital transmission technology which is considered to revolutionize the broadcasting industry in Zambia and set to be a technical solution to the many technical challenges inherent in the analogue terrestrial system. It is pertinent to disclose that digital technology has brought about qualitative signal processing, reception, reach and digital dividends which were never present in the analogue broadcasting era [5]. It is against this background that this study is conducted to assess the challenges and benefits of digital migration process in Zambia.

\subsection{Objectives of the Study}

The main research objective is to assess the challenges and benefits of digital broadcasting migration implementation process in Zambia.

To assess the main challenges associated with digital broadcasting migration in Zambia

To establish what benefits can be obtained as results of migrating from analogue to digital.

To assess the policy frame work which the Ministry of Information and Broadcasting has put in place after the successful digital migration.

\subsection{Research Questions}

What are the challenges and benefits of digital migration implementation in Zambia?

What are the main challenges associated with digital migration in Zambia?

What benefits can be obtained as results of migrating from analogue to digital?

What policy frame work has been put in place by the Ministry of Information and Broadcasting after the successful digital migration?

\subsection{Significance of the Study}

The study has the potential to help other African countries which are yet to implement or in the process of digital migration implementation. It is also aimed at making suggestions to overcome the identified challenges.

\section{Review of Literature}

Digital broadcasting explains the physical transfer of data in digital bit stream over a point-to-point, point-to-multipoint transmission medium or multi point to multipoint in discrete levels [20]. This can be over media such as copper wire, optical fiber, wireless communication media, and storage media. In digital video transmission, the cameras, recorders and studio equipment are digital. In addition, digital files are smaller compared to analog due to more sophisticated compression techniques. A digital signal is a discontinuous signal that changes from one state to another in discrete steps [6].

In Kenya's experience with the digital television migration included the key challenges faced and the solutions implemented to highlight valuable lessons that can provide useful information and guidance to regulators and policymakers [7].

In a related study the, ITU Regional Office for Asia and the Pacific indicated that the costs, enormity of task, lack of government support and cooperation among stakeholders, and ever evolving technologies remain as some of the challenges in the migration from analog to digital in the region [8]. He further noted that, not only is the setup of digital infrastructure expensive, also carrying out a simulcast service for a given period involves a lot of money and resources. Subsidizing set- top-boxes to make them affordable for the people is another additional cost.

Another study conducted by [9] also established that many governments still do not consider the digital migration as a priority hence the move is not fully endorsed or supported by the authorities and the necessary initiative and push. He further added that the move to digital is not initiated as a collective effort by private broadcasters, regulators and others in many countries. It was further established that the digital terrestrial transmission technologies are matured with a number of providers and supporters readily available. However, there are still cases where some still feel it may be better to wait for the next technology or next standard.

The study conducted in South Africa revealed that digital migration in Africa has rarely been discussed or taken into account [10]. The end of analog broadcasting and the production of dedicated equipment are likely to give rise to serious problems in Africa such as: problems of maintaining infrastructures which remain analog and the further 'Balkanisation' of African production, etc. In addition, the move to digital broadcasting brings with it other crucial challenges regarding regulation planning, pluralism of information, media development and access for all too new digital equipment, and increasing dependency beyond 
national borders in the sector [10].

\section{Research Methodology}

\subsection{Research Design}

In this study, a quantitative strategy was taken in the design, data collection and data analysis. Particularly, a cross-sectional survey was conducted, on a sample size of 300 individuals selected using a snowball sampling technique on the basis of sub-sectors, size, and location. Data was collected using a survey questionnaire, to be tested for reliability and validity using coefficient, and confirmatory factor analysis respectively. Finally, the survey questionnaire was self-administered by the researcher using a drop-pick method, and data collected, analysed using descriptive statistics and hypotheses tested with SPSS.

\subsection{Method of Data Collection}

For the purpose of this study, the researcher used both primary and secondary data. Secondary data gathered from different published reports by government sources, and other countries that have managed to successfully switch from analog to digital broadcasting. Primary data was collected using questionnaires.

\subsection{Sampling Design}

Sampling is the procedure a researcher uses to gather people, places or things to study. It is a process of selecting a number of individuals or objects from a population such that the selected group contains elements representative of the characteristics found in the entire group [11] The researcher used simple random sampling technique. The researcher will obtain a list of the 300 Zambia National Broadcasting Corporations (ZNBC) TV viewers and few selected people involved in the digital migration exercise.

\subsection{Methods of Data Analysis}

The collected qualitative data was analyzed using content analysis whereas quantitative data was analyzed using Statistical Package for Social Sciences (SPSS). These methods entail transcribing the recorded data and systematically identifying the major themes in the data and categorizing the data into common themes and testing it using statistical measures [12].

\section{Results}

The results obtained from the field study are represented using mean, Standard Deviation and Skewness. The results are presented using the objectives that were sent in section one of this study.

Objective one: To assess the main challenges associated with digital migration in Zambia

Table 1. Challenges of Digital migration.

\begin{tabular}{|c|c|c|c|}
\hline & Mean & Standard Deviation & Skewness \\
\hline Does the country have adequate infrastructure for digital migration? & 3.03 & 1.118 & .694 \\
\hline Does the country have adequate skilled personnel to facilitate the digital migration process? & 3.06 & 1.146 & -.040 \\
\hline Are there adequate funds available for digital migration project? & 2.84 & 1.127 & .437 \\
\hline Does the country have enough digital migration equipment to facilitate the process? & 3.24 & 1.234 & -2.18 \\
\hline
\end{tabular}

Objective Two: To establish what benefits can be obtained as results of migrating from analogue to digital.

Table 2. Benefits of Digital migration.

\begin{tabular}{llll}
\hline & Mean & Standard Deviation & Skewness \\
\hline One of the benefits of digital broadcasting migration is quality of transmission & 3.58 & 1.125 & .025 \\
Does digital migration help improving the content delivery than analog transmission? & 4.71 & 1.266 & 1.089 \\
I do understand that through digital migration, I can have more access to various TV channels. & 4.97 & 1.378 & .270 \\
I do understand that through digital migration, I can have better picture quality on my TV set. & 3.84 & 1.301 & .409 \\
\hline
\end{tabular}

Objective Three: To assess the policy frame work which the Ministry of Information and Broadcasting has put in place after the successful digital migration.

Table 3. Policy Framework of Digital migration.

\begin{tabular}{lccc}
\hline & Mean & Standard Deviation & Skewness \\
\hline $\begin{array}{l}\text { Has the government put policies in place to ensure the transition process from Analogue to Digital } \\
\text { broadcasting is a success? }\end{array}$ & 3.58 & 1.278 \\
$\begin{array}{l}\text { Does this policy framework for digital migration process involve subsidizing the acquisition of set top } \\
\text { boxes or TV Antenna? }\end{array}$ & 2.10 & 1.274 \\
$\begin{array}{l}\text { Does the policy framework ensure that it creates public awareness with regards to the importance of } \\
\text { digital migration process? }\end{array}$ & 1.35 & 2.137 \\
$\begin{array}{l}\text { Does the government policy attempt to make sure that the set top boxes or TV Antenna are readily } \\
\text { available? }\end{array}$ & .095 & .4 .07 \\
\hline
\end{tabular}




\section{Results Discussion}

As with regards to challenges of digital migration, the study wanted to establish whether the country had adequate infrastructure for digital migration. According to the results obtained and as depicted in Table, most respondents were neutral on this item in such a way that some indicated that the country has inadequate infrastructure for digital migration were as others were of the view that there was adequate infrastructure. This correlate with the findings of [8] in Kenya which revealed that not only does the setup of digital infrastructure expensive, also carrying out a simulcast service for a given period involves a lot of money and resources.

The study also further sought to determine whether there are adequate funds available for digital migration project in the country. The statistics obtained from these questions showed that the respondents disagreed to that there was no adequate funding for the digital migration process. Because of this, many of the challenges being talked about could have resulted. This is attributed to the mean scored which stands at 2.84 and standard deviation at 1.127 of the total response rate. The results correlate with those by [9] who indicated that lack of funding is a barrier to a successful migration process.

The study further established that the country did not have enough digital migration equipment to facilitate the process. Statistics from the data on this variable were above the mean as reflected by a mean of 3.24 and standard deviation of 1.234 .

At the same time the researcher sought to know whether one benefit of broadcast digital migration is quality transmission. The results obtained revealed the mean value of 3.58 and standard deviation of 1.125 . The skewness was .025 . This implies that the majority of the respondents stated that, quality transmission is one benefit of digital migration. The results correlated with those by [13]. It was also observed that digital migration has the potential to improve content delivery.

The researcher sought to establish whether or not the government had put policies in place to ensure the transition process from Analogue to Digital broadcasting is a success. Statistics from the data on this variable was slightly above the mean as reflected by a mean of 3.58 and standard deviation of 1.278. The results showed that the respondents slightly agreed that the government had put policies in place to ensure the transition process from Analogue to Digital broadcasting is a success.

In the same vain, the researcher sought to establish whether or not the policy framework ensure that it creates public awareness with regards to the importance of digital migration process. According to the results obtained and as indicated by the mean value of 1.35 and standard deviation of 2.137. The respondents agreed that the policy framework ensure that it creates public awareness with regards to the importance of digital migration.

\section{Conclusion}

The study of the challenges and benefits of digital migration process in Zambia has revealed that inadequate infrastructures for digital migration had impacted negatively on the implementation process. However, other factors that were considered to have had impacted negatively in the process include the fact that the country was not technologically prepared for the digital migration in terms of the skilled personnel to handle the technology among other things.

The study found that inadequate funding to the process by the government also hindered the process of migration. It was found that, funding to the process of migration in the country was not well coordinated as it kept delaying. These delays impacted negatively on the procurement of digital migration equipments. Since the country lacked, digital migration equipments, it was difficult to implement the process on time.

However, despite the challenges that have been outlined, the respondents revealed that there were a number of benefits associated with digital migration and prominent ones include, quality of transmission, improved content delivery, ability of the viewers to view more than one TV channel at once thereby giving them a better viewing pleasure.

The findings also revealed that, the government had put in place policy framework to ensure a successful migration process. It was established that the policy framework put in place meant to create awareness among the people of the benefits of digital migration.

\section{Recommendations}

That deliberate policies should have been put in place to ensure that the infrastructure needed for the digital migration are readily available.

Government policies should have been put in place to ensure that it creates public awareness with regards to the importance of the digital migration process to allow for more public participation.

Government should have ensured that the country has adequate skilled personnel to facilitate the digital migration process. This would have ensured that the process is completed on time and with fewer challenges.

Government should actualize the establishment of the content development fund to finance local content development. This will help create employment and ensure optimal utilization of channels.

That in the future whenever policy framework is being set, it should be able to outline the funding for the Digital migration process.

\section{Further Research}

Though there are a number of studies on the digital 
migration, continued research is needed to improve this study and to address its limitations. More research on digital migration in remote parts of the country must be explored. There is need to look into change of sources of funding for digital migration.

\section{Acknowledgements}

The authors would like to express their sincere gratitude to the Management of Copperbelt University Kapasa Makasa and Riverside Campuses for their support during the period of the study.

\section{References}

[1] Musa S. (2014) Guidelines for the Transition from Analogue to Digital Broadcasting-Including the Asia-Pacific Region, Telecommunication Development Sector, ITU, Geneva, Switzerland.

[2] Agona M \& Otim R [2011]), Guidelines for the transition from analogue to digital broadcasting, ITU, Lagos.

[3] Sam Agona and Sansa Otim Julliane, (2012). Mapping Digital Media: Kenya. A Report by the Open Societies Foundation. Open Society Foundations, United Kingdom.

[4] Ihechu M, (2012)- Media Law in South Africa. Kluver Law International: New York.

[5] B. Sanou, and F. Rancy (2012), Digital Dividend: Insight for spectrum decisions, ITU, Geneva, Switzerland.

[6] Jared Baraza, (2009). The Digital Dividend of Terrestrial Broadcasting, Springer, Dordrecht Heidelberg, Germany.

[7] Telecommunications Management Group inc, 2017Publication Television Archiving, ABU Malaysia.

[8] Wisit Atipayakoon (2017) (ABU) - Publication File Formats for sound programme exchange, Archives at Risk Alliance: www.archivesatrisk.org.

[9] Chang Jin (2017) Systems Architecture, Services and Functionality" Geneva December 2017, page 111.
[10] SA Time Publication (2014), SADC Roadmap for Digital Broadcasting Migration, Johannesburg, South Afric.

[11] Azhar D (2002), Digital broadcasting state of play - SADC Opportunities, Challenges and Possibilities, Pretoria, South Africa, 2014.

[12] Fox Tewksbury. (2009) Qualitative Versus quantitative Methods: Understanding why Qualitative methods are Superior for Criminology and Criminal Justice. Journal of Theoretical and Philosophical Criminology, Vol 1. P.

[13] Butcher me, "Digital Video Archives - facing the facts" EBU Technical Review - Geneva Summer 201711 pages. Dublin Core Metadata Initiative; http://dublincore.org/.

[14] EBU Project Group P/FTA (Future Television Archives), "Supplement to the EBU Report Future content Management Systems Architecture, Services and Functionality" Geneva December 2016.

[15] European Broadcasting Union (EBU), “Technical Report 003, Radio Archives: Conception and Practice, Geneva July 2017.

[16] European Broadcasting Union (EBU) "Recommendation R105-2008 Digitisation of programmed material in Audio Archives: Geneva March 2015.

[17] Ardizzone L and Ferrari R (2010). The Challenges of digitisation of broadcasting in Nigeria: Department of Mass Communication, Abia State University. [Online]. Available: http://.iiste.org/Journals/index.php/NMMC/article/viewFile/31 14/3155. Accessed on 20/08/2018.

[18] Bunshak, T. (2006). Digital broadcasting is now. NBC News. 8 (2).

[19] Burrows R. (2014). Media Law in South Africa. Kluver Law International: New York.

[20] Digital Migration Policy For Television Broadcasting in Uganda. 2011. [Report] Uganda by Ajzen (2014).

[21] Hanson Edmunson. (2005). ICT Lawyers. [Online]. Available: http://www.kerronedmunson.co.za/resources/dtt-article-keoct-2011.pdf. 